\title{
Experimental Investigation into Corrosion Effect on Mechanical Properties of High Strength Steel Bars under Dynamic Loadings
}

\author{
Hui Chen $\left(\mathbb{D},{ }^{1,2}\right.$ Jinjin Zhang $\left(\mathbb{D},{ }^{1}\right.$ Jin Yang, ${ }^{1}$ and Feilong Ye ${ }^{1}$ \\ ${ }^{1}$ Department of Building Engineering, Oujiang College, Wenzhou University, Wenzhou 325035, China \\ ${ }^{2}$ Department of Structural Engineering, Tongji University, Shanghai 200092, China \\ Correspondence should be addressed to Hui Chen; chenhui0306@wzu.edu.cn
}

Received 15 June 2017; Revised 17 November 2017; Accepted 7 December 2017; Published 1 January 2018

Academic Editor: Ramazan Solmaz

Copyright (c) 2018 Hui Chen et al. This is an open access article distributed under the Creative Commons Attribution License, which permits unrestricted use, distribution, and reproduction in any medium, provided the original work is properly cited.

\begin{abstract}
The tensile behaviors of corroded steel bars are important in the capacity evaluation of corroded reinforced concrete structures. The present paper studies the mechanical behavior of the corroded high strength reinforcing steel bars under static and dynamic loading. High strength reinforcing steel bars were corroded by using accelerated corrosion methods and the tensile tests were carried out under different strain rates. The results showed that the mechanical properties of corroded high strength steel bars were strain rate dependent, and the strain rate effect decreased with the increase of corrosion degree. The decreased nominal yield and ultimate strengths were mainly caused by the reduction of cross-sectional areas, and the decreased ultimate deformation and the shortened yield plateau resulted from the intensified stress concentration at the nonuniform reduction. Based on the test results, reduction factors were proposed to relate the tensile behaviors with the corrosion degree and strain rate for corroded bars. A modified Johnson-Cook strength model of corroded high strength steel bars under dynamic loading was proposed by taking into account the influence of corrosion degree. Comparison between the model and test results showed that proposed model properly describes the dynamic response of the corroded high strength rebars.
\end{abstract}

\section{Introduction}

Structure deterioration induced by corrosion of reinforcing bars is one of the major problems in civil engineering. The corrosion of reinforcing bars (rebars) not only leads to the cracking of the concrete cover, but also causes the serious damage of Reinforced concrete (RC) structures. Therefore, investigation of the deterioration of mechanical properties of corroded steel bars is crucial for predicting the serviceability and durability of RC structures [1]. The static tensile test results of corroded rebars have shown that, with the development of the corrosion degree, the nominal yield and ultimate strengths and the ultimate strain of a corroded rebar decrease. Meanwhile, the yield plateau shortens or even disappears $[2,3]$. Empirical formulas have been proposed to evaluate the yield and ultimate strengths of corroded reinforcing bars [4, 5], and the mathematical models of stress-strain relationship for corroded rebars in different environment condition have also been established [6-10].
RC structures may suffer impact or explosion loads during their service life, such as bridge and underground protective structures [11]. The strain rate of rebars in concrete structures may reach $10 \mathrm{~s}^{-1}$ under impact loading. Evident effects of strain rates on the mechanical properties of rebars are found in their tensile tests under a high strain rate [12]. Both their yield and ultimate strengths increase when the strain rate is increased, but the yield strength has a more obvious increment than the ultimate strength $[13,14]$. The test results of corroded medium and low strength rebars under dynamic loadings have indicated that the strain rate effect decreased with the increase of corrosion degree [15]. In recent years, more and more high strength steel bars are being used in modern RC structure because of their good strength and ductility combination. However, the effect of corrosion and strain rate on the mechanical properties of high strength rebars has not been discussed.

With the development of computer technology, finite element simulation has played a key role, especially in the 
TABLE 1: Chemical composition (by mass ${ }^{\mathrm{a}}$ ) of steel bar HRB500 (\%).

\begin{tabular}{lccccccccc}
\hline $\mathrm{C}$ & $\mathrm{Si}$ & $\mathrm{Mn}$ & $\mathrm{P}$ & $\mathrm{S}$ & $\mathrm{Cr}$ & $\mathrm{Mo}$ & $\mathrm{V}$ & $\mathrm{Ni}$ & $\mathrm{Cu}$ \\
\hline 0.24 & 0.27 & 1.44 & 0.03 & 0.02 & 0.08 & $<0.02$ & 0.10 & 0.022 & 0.02 \\
\hline
\end{tabular}

${ }^{\mathrm{a}}$ The balance was Fe.

engineering area. An ideal constitutive model should be able to precisely predict the behaviors of materials under different loading conditions, such as static and dynamic modes and low and high strains, as many engineering materials behave significantly different under different loading conditions. A variety of rate dependent constitutive models have been proposed for high strain rate metal materials, such as JohnsonCook (J-C) model and Cowper-Symonds model. Among them, The J-C constitutive model is one of the most widely used models because it performs in a simple yet effective manner [16]. As a semiempirical model, it describes the behaviors of plastic materials at high strains, high strain rates, and high temperatures. However, the existing J-C constitutive model does not consider the coupled effect of strain rate and corrosion degree on flow stress, causing limited capability of predicting material properties.

The intention of this paper is to experimentally investigate the effect of corrosion on mechanical properties of corroded high strength steel. A comprehensive test program is designed to observe, monitor, and evaluate corrosion behavior of corroded high steel bars and its effect on their mechanical properties in concrete under static and dynamic loading. The high strength rebars with different corrosion degrees were got by the impressed current method in concrete. To investigate the impact of corrosion degree on its mechanical properties under dynamic loading, tensile tests were conducted on the corroded high strength rebars by using a high strain rate test system. The mechanical performance characteristics (yield strength, ultimate strength and ultimate strain, etc.) were examined. Based on the test results, reduction factors were proposed to relate the tensile behaviors with the corrosion degree and strain rate for corroded bars and a modified model of Johnson-Cook strength for corroded high strength steel bars under dynamic loading was proposed by taking into account the influence of corrosion. The results produced from the tests can contribute to the body of knowledge of corrosion behavior and its effect on mechanical properties of corroded rebars under dynamic loading, which can be used to predict mechanical behavior of corroded RC structures under impact loading.

\section{Experimental Program}

2.1. Materials and Specimens. The high strength rebars HRB500 commonly used in China were used to investigate the impact of strain rate and corrosion on the mechanical behavior of rebars under static and dynamic loading. HRB500 rebars refer to the hot rolled ribbed rebar with the yield strength not less than $500 \mathrm{MPa}$. Their original diameters were $25 \mathrm{~mm}$.

As is well known, the mechanical properties of metal are affected by its chemical composition, morphology, and

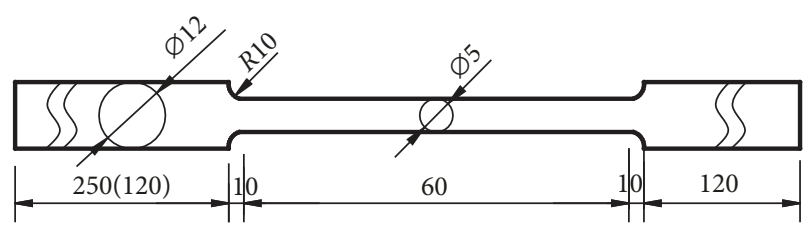

FIGURE 1: Dimension of specimens (Unit: $\mathrm{mm}$, not to scale).

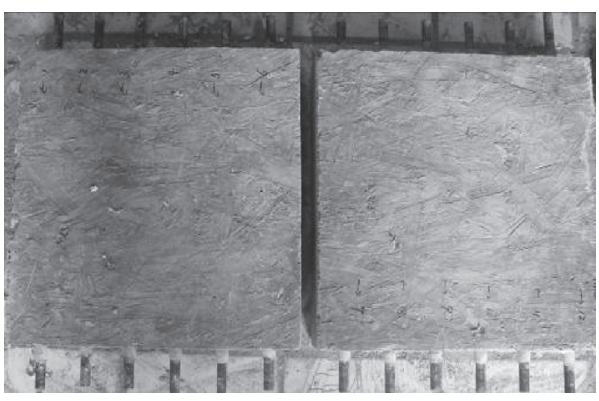

FIGURE 2: Preparation of RC slabs for the accelerated corrosion process.

microstructure which vary significantly. The chemical composition of HRB500 steel bar was tested before accelerated corrosion test, and the results are shown in Table 1. The standard specimens were made according to the ASTM-E809 standard [17] as shown in Figure 1, the reduced section was $5 \mathrm{~mm}$ in diameter and $60 \mathrm{~mm}$ in length, and the section of grip part was $12 \mathrm{~mm}$ in diameter. The length of grip part for strain rates ranging from $0.0002 \mathrm{~s}^{-1}$ to $0.1 \mathrm{~s}^{-1}$ was $70 \mathrm{~mm}$ and for strain rates ranging from $2 \mathrm{~s}^{-1} \sim 50 \mathrm{~s}^{-1}$ was $250 \mathrm{~mm}$ and $120 \mathrm{~mm}$ at two ends, respectively. Both ends of each rebar were extended $50 \mathrm{~mm}$ beyond the desired length for the connection with electric wires.

The grip parts of the specimens, which would not be expected to corroded, were wrapped by epoxy. Then, rebar specimens were embedded in concrete as shown in Figure 2, and the reduced sections of specimens were corroded by the impressed current method. The constituents of the concrete used for the preparation of the corroded high strength specimens consisted of ordinary Portland cement, sand with a maximum diameter of $5 \mathrm{~mm}$, coarse aggregate with a maximum diameter of $15 \mathrm{~mm}$, and tap water. Cubic samples with the dimension of $150 \times 150 \times 150 \mathrm{~mm}^{3}$ were prepared. Mix proportion of the concrete mixtures is shown in Table 2. The 28-day axial compressive strength of concrete was found to be $29.5 \mathrm{MPa}$ on an average.

2.2. Accelerated Corrosion Test. The concrete slab specimens of high strength rebars were cured in a natural indoor 
TABLE 2: Mix proportion of the concrete mixtures.

\begin{tabular}{ccccc}
\hline w/c & Cement $/ \mathrm{kg} / \mathrm{m}^{3}$ & Sand $/ \mathrm{kg} / \mathrm{m}^{3}$ & Coarse aggregate $/ \mathrm{kg} / \mathrm{m}^{3}$ & $\mathrm{Water} / \mathrm{kg} / \mathrm{m}^{3}$ \\
\hline 0.50 & 674 & 506 & 1031 & 337 \\
\hline
\end{tabular}

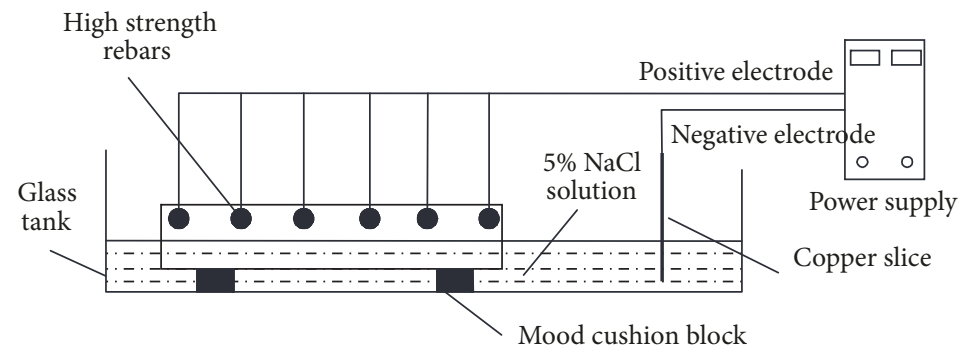

(a) Accelerated corrosion test setup

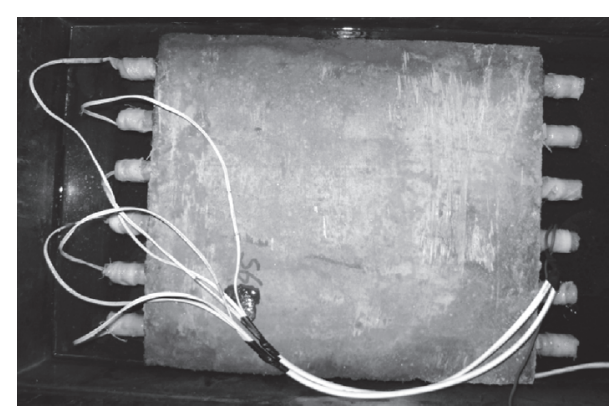

(b) Accelerated corrosion test site

FIGURE 3: Accelerated corrosion test.

environment and room temperature for 28 days after casting. Then they were placed into glass tanks and partially immersed in $5 \% \mathrm{NaCl}$ solution. The solution level in the tanks was controlled to be about $30 \mathrm{~mm}$ lower than the lower surface of the rebars, as shown in Figure 3. In the previous studies on mechanical properties of corroded rebars, accelerated corrosion by means of the impressed current technique is widely used to obtain corroded rebars because of its advantages in terms of time and cost, and its feasibility to control the rate of corrosion $[18,19]$. There are some differences between accelerated corrosion and natural corrosion in corrosion products, distribution of corrosion expansion force, and distribution of bond stress [20]. However, when the implied current density is less than $200 \mu \mathrm{A} / \mathrm{cm}^{2}$, the differences between naturally corroded rebars and artificially corroded rebars could be neglected [15]. The rebars subject to both natural corrosion and accelerated corrosion showed the similar degradation of mechanical properties [3]. A constant current was applied during the corrosion process to generate a constant current density of $100 \mu \mathrm{A} / \mathrm{cm}^{2}$. Based on Faraday's law, the total current required was calculated based on the respective steel surface area and was checked regularly to adjust for any drift. The targeted average corrosion degrees of the specimens were listed in Table 3. Based on Faraday's law of induction [21], as given in (1), the required time for the prescribed corrosion degrees of $0.05,0.10,0.15,0.20$, and 0.25 was 25 days, 50 days, 75 days, 100 days, and 125 days, respectively. Corrosion current was measured every day in the first week of the test and then weekly until the end of tests:

$$
t_{\mathrm{c}}=\frac{Z F \cdot r \cdot \rho \eta_{\mathrm{sp}}}{86400 \cdot 2 A_{\mathrm{Fe}} \cdot i}
$$

where $A_{\mathrm{Fe}}$ is the atomic mass of iron $(A=56 \mathrm{~g}), t_{\mathrm{c}}$ is corrosion duration (days), $Z$ is the valence of iron, which is 2 in this case (iron), $F$ is Faraday's constant ( $96500 \mathrm{~A} \cdot \mathrm{s}$ ), $i$ is the density of impressed current $\left(\mathrm{A} / \mathrm{cm}^{2}\right), \rho$ is the mass density of iron $\left(\mathrm{g} / \mathrm{cm}^{3}\right), r$ is the radius of to-be-corroded rebars $(\mathrm{mm})$, and $\eta_{\mathrm{sp}}$ is the targeted average corrosion degree.
TABLE 3: Test results of corroded high strength steel bars.

\begin{tabular}{|c|c|c|c|c|}
\hline Specimen & $\eta_{\mathrm{s}}$ & $\eta_{\mathrm{s}, \max }$ & $\begin{array}{c}f_{\mathrm{yc}} \\
(\mathrm{MPa})\end{array}$ & $\begin{array}{c}f_{\mathrm{uc}} \\
(\mathrm{MPa})\end{array}$ \\
\hline HSO0-00 & 0 & 0 & 499.11 & 639.16 \\
\hline HS05-00 & 0.05 & 0.064 & 469.06 & 597.91 \\
\hline HS15-00 & 0.14 & 0.171 & 412.53 & 516.93 \\
\hline HS20-00 & 0.19 & 0.231 & 395.21 & 496.05 \\
\hline HS25-00 & 0.25 & 0.288 & 361.60 & 463.97 \\
\hline HS00-0.01 & 0 & 0 & 528.65 & 666.67 \\
\hline HS00-0.1 & 0 & 0 & 541.89 & 676.85 \\
\hline HSO0-2 & 0 & 0 & 573.47 & 696.21 \\
\hline HS00-10 & 0 & 0 & 592.31 & 706.90 \\
\hline HSO0-50 & 0 & 0 & 611.66 & 727.78 \\
\hline HS05-10 & 0.054 & 0.064 & 562.26 & 664.63 \\
\hline HS15-10 & 0.145 & 0.174 & 503.18 & 580.09 \\
\hline HS20-10 & 0.201 & 0.241 & 479.25 & 557.17 \\
\hline HS25-10 & 0.247 & 0.296 & 444.10 & 519.99 \\
\hline HS10-00 & 0.098 & 0.118 & 439.01 & 564.81 \\
\hline HS10-0.01 & 0.095 & 0.114 & 470.59 & 589.76 \\
\hline HS10-0.1 & 0.097 & 0.116 & 472.12 & 609.12 \\
\hline HS10-2 & 0.104 & 0.124 & 496.56 & 611.66 \\
\hline HS10-10 & 0.096 & 0.115 & 522.54 & 625.92 \\
\hline HS10-50 & 0.105 & 0.126 & 528.14 & 644.77 \\
\hline
\end{tabular}

Notes. (1) The number of a specimen, HSAA-BB, represents high strength steel rebar HRB500 with the targeted amount of corrosion, $\eta_{\mathrm{sp}}=0$. AA under strain rate of $\mathrm{BBs}^{-1}$; (2) $\eta_{\mathrm{s}}$ is the average corrosion degree. $\eta_{s, \max }$ is the maximum corrosion degree. $f_{\mathrm{yc}}$ and $f_{\mathrm{uc}}$ are the corresponding yielding and ultimate loads measured during the tensile tests of the corroded high strength rebars $(\mathrm{MPa})$, respectively.

After the completion of each corrosion test, the slab was broken, and the corresponding rebars were then collected. The accelerated corroded rebars were cleaned using a hydrochloric acid solution and dried according to ASTM G1-03 standard [22], as shown in Figure 4. 


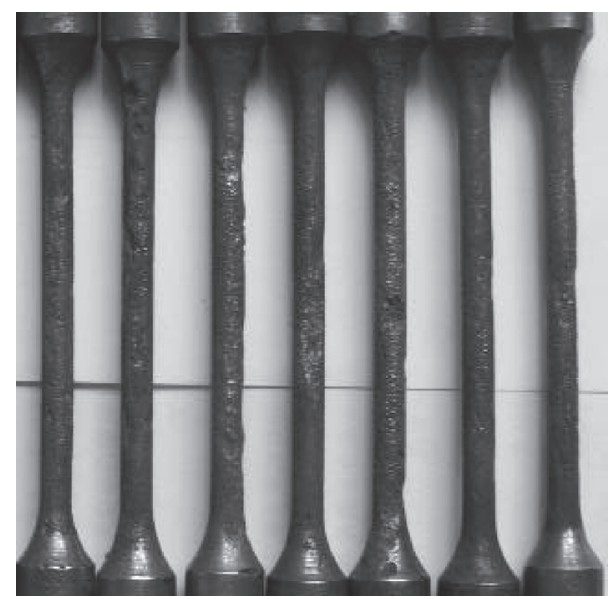

FiguRE 4: Corroded rebars after the accelerated corrosion process.

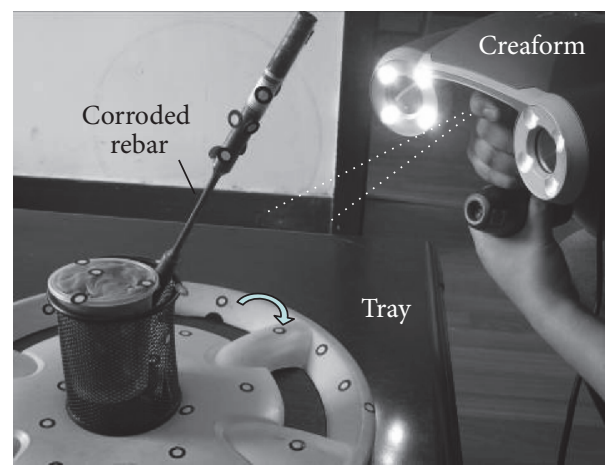

FIGURE 5: Three-dimensional laser scanner.

2.3. Measurement of Corrosion Degree. After acid cleaning and drying, geometric models of all corroded rebars were built using a 3D laser scanner (Creaform) with high measuring accuracy, convenient operation, automatic reconstruction of $3 \mathrm{D}$ objective shapes, and high repeatability, as shown in Figure 5. Figure 6 shows a comparison between a photo of a corroded rebar after acid cleaning and the corresponding $3 \mathrm{D}$ geometric model, which indicates that the accuracy of the 3D laser scanning (i.e., $0.04 \mathrm{~mm}$ ) was satisfactory.

Through observation of the virtual models, it was clear that the corrosion was not evenly distributed circumferentially and longitudinally, as seen in Figure 6. ProEngineer software was used to obtain the areas of the discrete cross sections along the longitudinal axis of each corroded rebar at intervals of $1 \mathrm{~mm}$. Accordingly, the average corrosion degree and the maximum corrosion degree were shown in Table 3.

Figures 7(a) and 7(b) indicate some typical profiles at different corrosion levels. The profiles of these cross sections were obtained from the orthographic projections of the intersection line between the cutting plane and the rebar surface. The inner irregular curve represents the profile of corroded cross sections, while the external thin circle indicates the outline of the sound steel bars. The corrosion degree was marked in the figures. The numbers on the top and below in Figures 7(a) and 7(b) represent the maximum corrosion

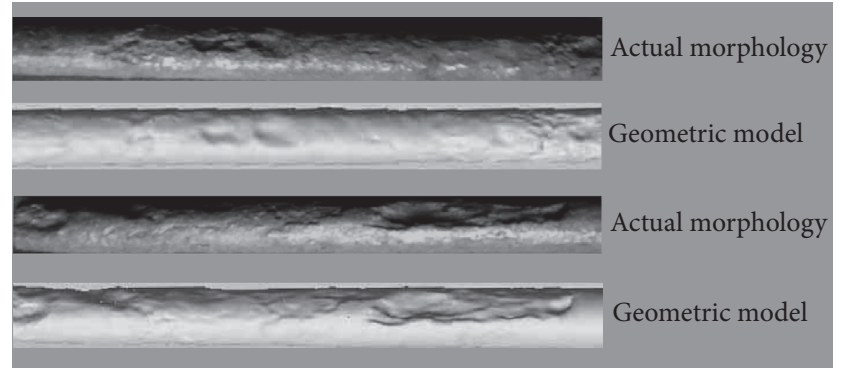

Figure 6: Actual corroded rebar and its 3D geometric model.

degree and the average corrosion degree, respectively. The maximum corrosion degree ranged from 0.064 to 0.296 for corrosion pit. From Figure 7, it can be seen that the corrosion penetration is far from circumferentially uniform. Through visual observation, the different pit shapes could be wide and shallow, elliptical, or even undercutting.

2.4. Tensile Tests of Corroded High Strength Rebars under Static and Dynamic Loading. After evaluating corrosion levels, the corroded bars were subjected to displacementcontrolled tensile testing. The tensile tests for specimens were completed on an Instron VHS160/100-20 testing machine with strain rates of $2 \mathrm{~s}^{-1} \sim 50 \mathrm{~s}^{-1}$, in which the deformation of a rebar was measured by using laser displacement meters with a data acquisition frequency of $1000 \mathrm{~Hz}$, as shown in Figure 8(a). The tensile tests for specimens were completed on a Zwick electronic testing machine with strain rates of $0.0002 \mathrm{~s}^{-1} \sim 0.1 \mathrm{~s}^{-1}$. An extensometer with a data acquisition frequency of $100 \mathrm{~Hz}$ was installed in the middle of a rebar specimen, with the gauge length of $50 \mathrm{~mm}$, as shown in Figure $8(\mathrm{~b})$. The static and dynamic loading material properties (elastic modulus, nominal yield stress, and ultimate tensile stress) were measured according to the ASTM E8 standard on tensile testing equipment. The yield and ultimate loads of the specimens are shown in Table 3.

\section{Experimental Results and Discussion}

3.1. Failure Modes. The typical failure modes of the specimens are shown in Figure 9; by comparing the broken section of corroded rebars, it was found that there were no obvious differences in the necking zones among the specimens with the same corrosion degree under the static and dynamic loading. However, most of the corroded rebars broke in the minimum cross section. The necking phenomenon disappeared gradually with the increase of the corrosion degree, which means that the deformation ability of the high strength rebar decreased.

3.2. Stress-Strain Curves. The strain of the test bar was determined by dividing the increase of the gauge length by the initial gauge length. Three methods were mainly used in earlier studies to calculate the stress of a corroded steel bar from the measured force, which are based on the average reduced cross-sectional area $[3,5]$, the original 


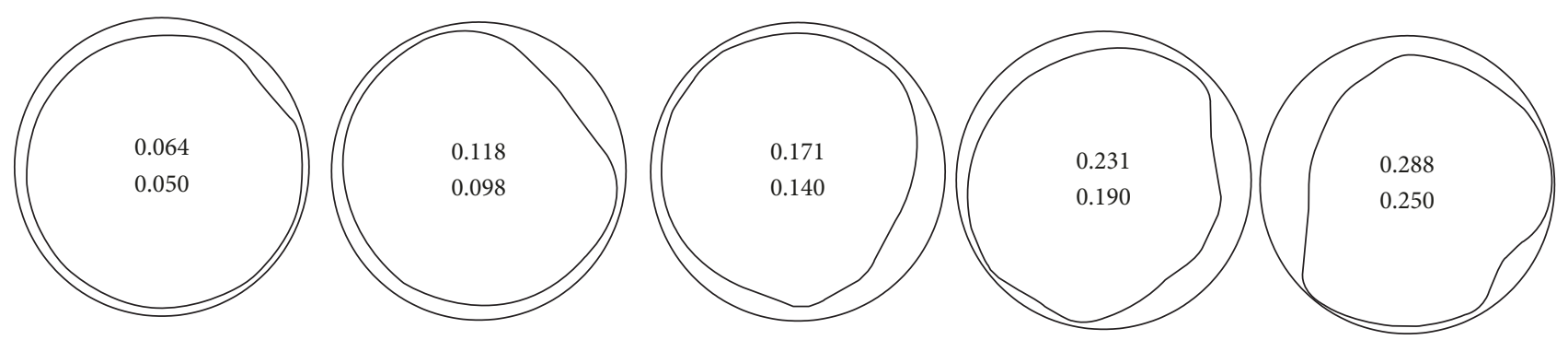

(a) HS05-00, HS10-00, HS15-00, HS20-00, and HS25-00

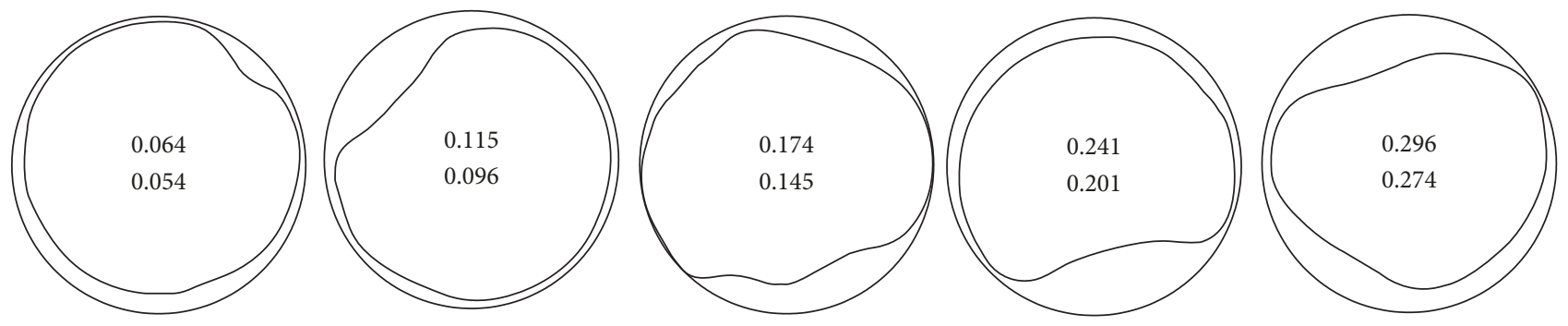

(b) HS05-10, HS10-10, HS15-10, HS20-10, and HS25-10

Figure 7: Typical cross-sectional profiles of bars under accelerated corrosion.

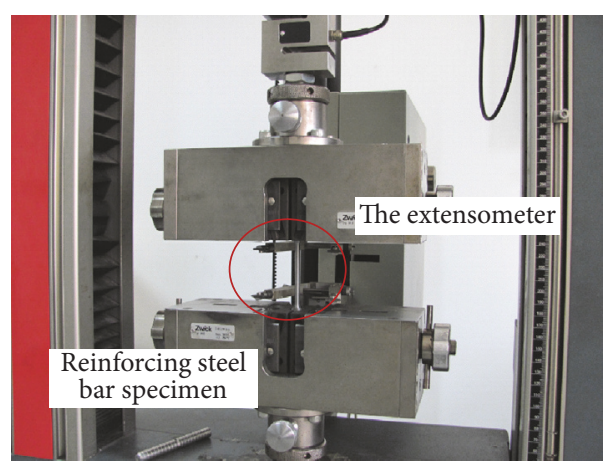

(a) Zwick electronic testing machine

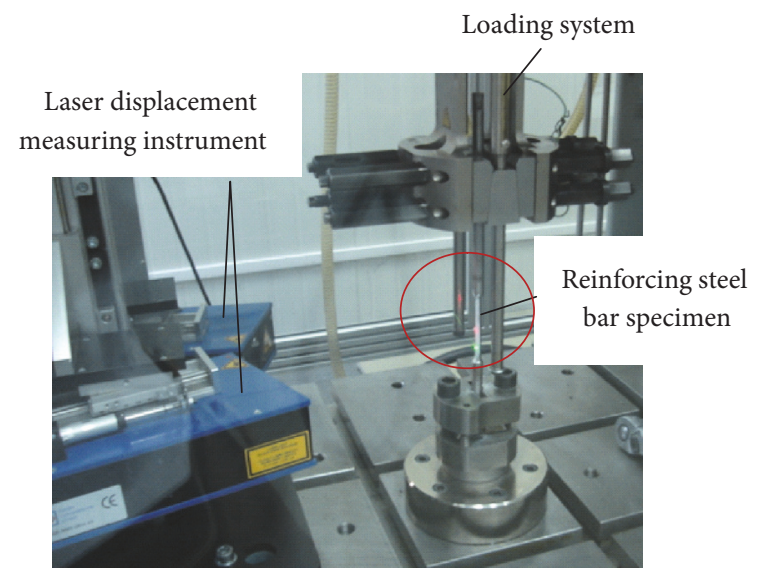

(b) Instron VHS160/100-20 testing machine

Figure 8: Tensile test stand and dimension of specimens.

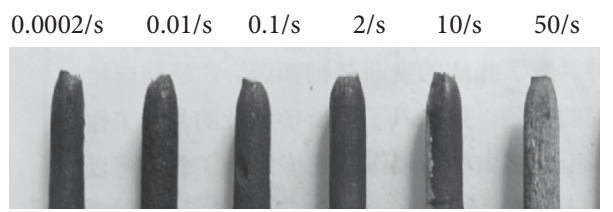

(a)

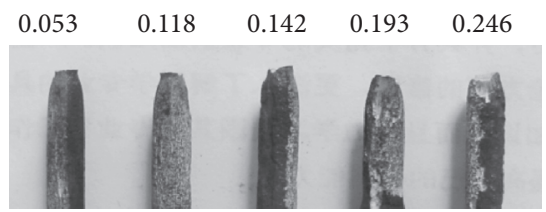

(b)

FIGURE 9: Failure modes of corroded rebars (a) Specimens of HRB 500 with corrosion degree of 0.10 under different strain rates. (b) Specimens of HRB 500 with different corrosion degree under static loads.

cross-sectional area [6], and the smallest cross-sectional area of the bar, respectively [15]. There is no consensus among researchers regarding which method is more appropriate than the others. However, the method based on the original cross-sectional area was used in most of the previous studies. This research adopted it to calculate the stress of corroded bars.
The measured engineering nominal stress-strain curves are presented in Figure 10 and the resulting average true stress-strain curve was got and determined with (2) and (3):

$$
\begin{aligned}
\widetilde{\varepsilon} & =\ln (1+\varepsilon), \\
\widetilde{\sigma} & =\ln (1+\sigma),
\end{aligned}
$$




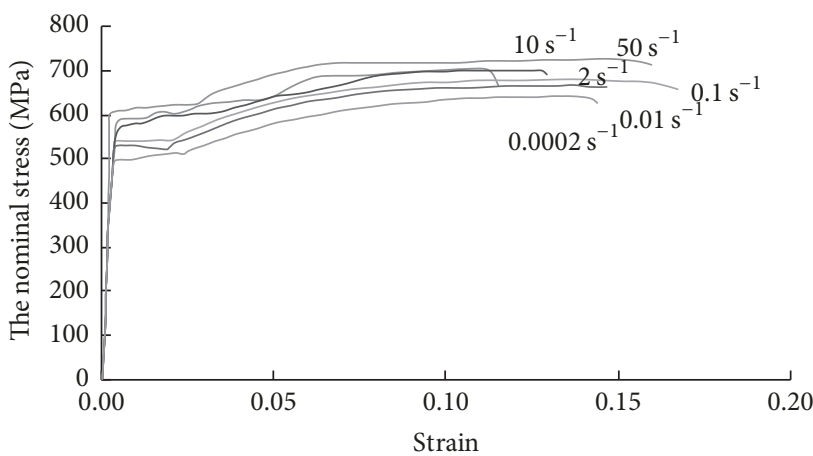

(a) The uncorroded specimens under different strain rates

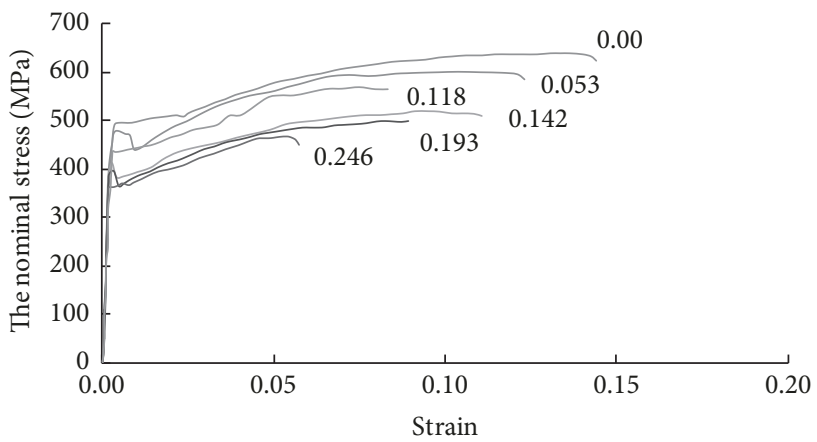

(c) Specimens with $0.0002 \mathrm{~s}^{-1}$ under different corrosion degree

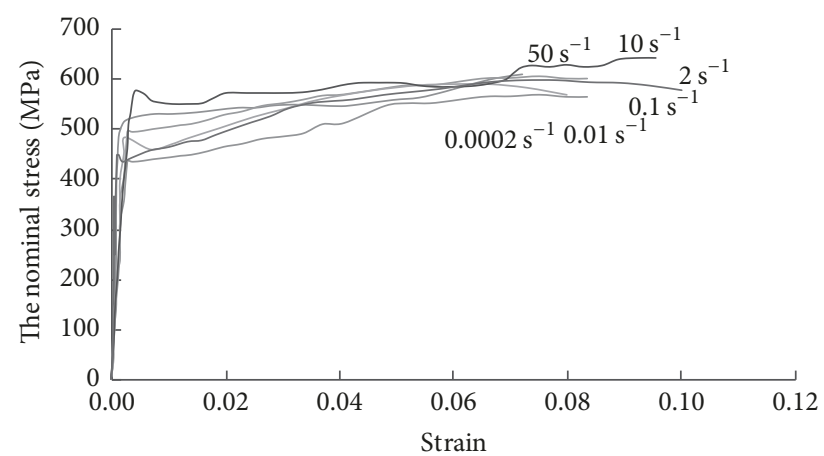

(b) Specimens with corrosion degree of 0.10 under different strain rates

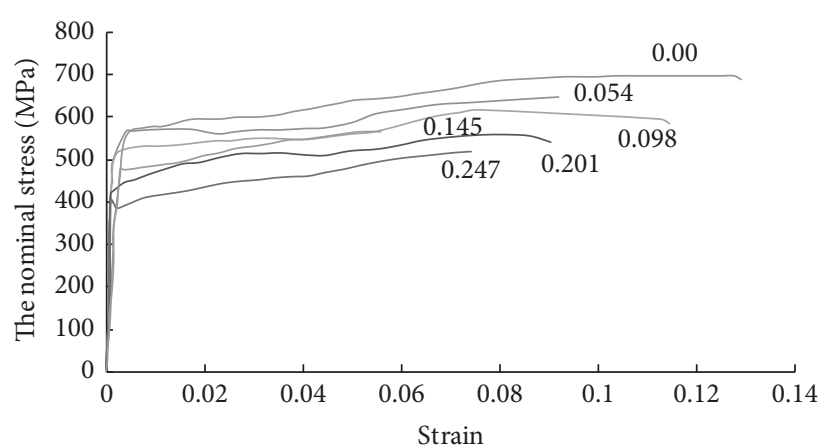

(d) Specimens with $10 \mathrm{~s}^{-1}$ under different corrosion degree

FIgURE 10: The nominal stress-strain curves.

where $\varepsilon$ and $\sigma$ were the corresponding average engineering strain and stress $(\mathrm{MPa})$, respectively. $\widetilde{\varepsilon}$ and $\widetilde{\sigma}$ were the true strain and stress $(\mathrm{MPa})$, respectively.

The typical nominal stress-strain curves for specimens with different corrosion degrees are shown in Figures 10(a)-10(d). The number near a curve in Figures 10(a) and 10 (b) stands for the strain rate; and the numbers near a curve in Figures 10(c) and 10(d) represent the average corrosion degree, respectively. The yield and ultimate strengths of the specimens are given in Table 3 . The results showed that the mechanical properties of corroded high strength steel bars were strain rate dependent. Both the yield and ultimate load increased as the strain rate increased. It can be seen that, with the development of corrosion degree, the nominal yield strength, ultimate strength, and ultimate deformation decreased under dynamic loading, and the yield plateau shortened or even disappeared completely. Both the nominal strength and deformation capacities of corroded high strength bars tended to decrease with increasing corrosion degree. However, the trend was less clear for the deformation capacity than for the nominal strength. This is due to the fact that the nominal yield and strength capacity was mainly related to the minimum cross-sectional area while the deformation capacity was not only related to the minimum cross-sectional area but also related to the shape change along the bar, as shown in Figure 11, which shows the distribution of cross-sectional areas along the length of the bar obtained from the 3D scan for corroded rebars HS15-00 and HS20-00. This is consistent with the findings from Zhang et al. [3, 15] that the decreased nominal yield and ultimate strengths of

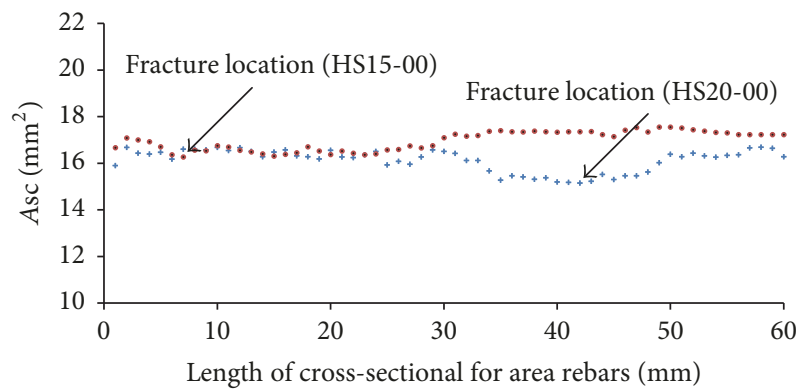

FIGURE 11: Distribution of cross-sectional areas for corroded rebars HS15-00 and HS20-00.

the corroded rebars were mainly caused by the reduction of cross-sectional areas for rebars, and the decreased ultimate deformation and the shortened yield plateau resulted from the intensified stress concentration at the corrosion pitting.

\section{Development of the Modified J-C Model for Corroded High Strength Rebars}

4.1. Original J-C Model. The normal equation of J-C model is as follows [16]:

$$
\sigma_{\mathrm{s}}=\left[A+B\left(\varepsilon^{p}\right)^{n}\right]\left[1+C \ln \frac{\dot{\varepsilon}^{p}}{\dot{\varepsilon}_{1}}\right]\left[1-T^{* m}\right],
$$

where $\sigma_{\mathrm{s}}$ is the Von Mises equivalent flow stress (MPa), $A$ is the yield stress at a given reference temperature and 
a given reference strain rate, $B$ is the coefficient of strain hardening, $C$ is the coefficient of strain rate hardening, $n$ is the strain hardening exponent, $\varepsilon^{p}$ is the equivalent plastic strain, and $\dot{\varepsilon}^{*}=\dot{\varepsilon} / \dot{\varepsilon}_{0}$ is the dimensionless strain rate with $\dot{\varepsilon}$ being the strain rate and $\dot{\varepsilon}_{0}$ the reference strain rate. $T^{*}=$ $\left(T-T_{\mathrm{r}}\right) /\left(T-T_{\mathrm{r}}\right)\left(T_{\mathrm{m}}-T_{\mathrm{r}}\right) \cdot\left(T_{\mathrm{m}}-T_{\mathrm{r}}\right)$ is the dimensionless temperature, $T$ is the experimental temperature $\left({ }^{\circ} \mathrm{C}\right), T_{\mathrm{r}}$ is the room temperature $\left({ }^{\circ} \mathrm{C}\right)$, and $T_{\mathrm{m}}$ is the melting temperature of the materials $\left({ }^{\circ} \mathrm{C}\right)$.

In (3), the items $\left[A+B\left(\varepsilon^{p}\right)^{n}\right],\left[1+C \ln \left(\dot{\varepsilon}^{p} / \dot{\varepsilon}_{1}\right)\right]$, and $\left[1-T^{* m}\right]$ are used to describe the work hardening effect, the strain rate effect, and the temperature effect, respectively. The parameter $A$ is a material constant, $B$ is a preexponential factor, $n$ is a strain hardening coefficient, and $C$ and $m$ are strain rate effective factor and temperature effective factor, respectively.

4.2. Development of the Modified J-C Model. Based on the test results of the mechanical properties of corroded high strength rebars under dynamic loading, the nominal stressstrain relationship of the J-C model for corroded rebars under dynamic loading was proposed, as shown in Figure 12. In the proposed model, the average corrosion degree $\eta_{\mathrm{s}}$ was used, because it can be measured easily in practice and reflect overall corrosion of rebars. The nominal stress of the corroded rebar is the ratio of the applied load and the average corrosion degree, which can be calculated using the average corrosion degree and the original cross-sectional area before corrosion. When the corrosion degree is relatively small, the yield plateau does not disappear, and the J-C model is used. When the corrosion degree exceeds a critical value, the yield plateau $\eta_{\mathrm{s}, \mathrm{cr}}$ disappears, and the nonlinear model is used. Meanwhile, as the strain rate increases, the yield and ultimate strengths of corroded rebars increase, and the ultimate strain may be assumed to remain unchanged.

Based on the J-C model stress-strain relationship of uncorroded rebars, the stress-strain relationship of J-C model for corroded high strength rebars under dynamic loading can be expressed as

$$
\begin{aligned}
& \sigma_{\mathrm{sc}, \mathrm{d}} \\
& = \begin{cases}E \varepsilon_{\mathrm{sc}, \mathrm{d}} & 0<\varepsilon_{\mathrm{sc}, \mathrm{d}} \leq \varepsilon_{\mathrm{syc}, \mathrm{d}} \\
f_{\mathrm{syc}, \mathrm{d}} & \varepsilon_{\mathrm{syc}, \mathrm{d}}<\varepsilon_{\mathrm{sc}, \mathrm{d}} \leq \varepsilon_{\mathrm{shc}, \mathrm{d}} \\
{\left[A+B\left(\varepsilon^{p}\right)^{n}\right]\left[1+C \ln \frac{\dot{\varepsilon}^{p}}{\dot{\varepsilon}_{1}}\right]} & \varepsilon_{\mathrm{shc,d}}<\varepsilon_{\mathrm{sc}, \mathrm{d}} \leq \varepsilon_{\mathrm{suc}, \mathrm{d}},\end{cases}
\end{aligned}
$$

where $\sigma_{\text {sc,d }}$ is the Von Mises equivalent flow stress of the corroded rebars $(\mathrm{MPa}), A$ is the yield stress at a given reference strain rate $(\mathrm{MPa}), B$ is the coefficient of strain hardening, $C$ is the coefficient of strain rate hardening, $n$ is the strain hardening exponent, $\varepsilon$ is the equivalent plastic strain, and $\dot{\varepsilon}^{*}=\dot{\varepsilon} / \dot{\varepsilon}_{0}$ is the dimension less strain rate with $\dot{\varepsilon}$ being the strain rate and $\dot{\varepsilon}_{0}$ the reference strain rate. Here, $\dot{\varepsilon}_{0}=10^{-3} \mathrm{~s}^{-1}$. $E_{\mathrm{sc}, \mathrm{d}}$ is Young's modulus for corroded rebars under high strain rates; $\varepsilon_{\text {syc,d }}$ is the yielding strain; $\varepsilon_{\text {shc,d }}$ is the hardening strain; $\varepsilon_{\text {suc,d }}$ is the ultimate strain, which is assumed to be equal to the ultimate strain under static load, $\varepsilon_{\text {suc,d }}=\varepsilon_{\text {suc,st }} ; f_{\mathrm{yc}, \mathrm{d}}$ and

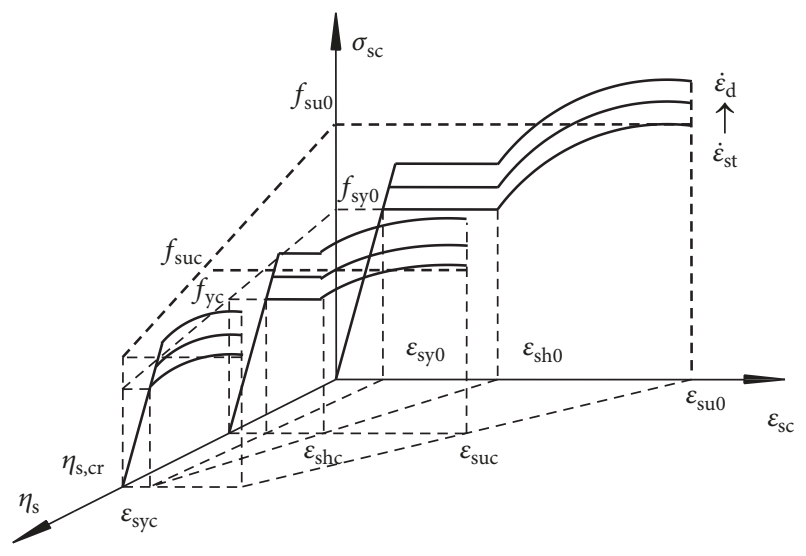

FIGURE 12: Johnson-Cook model of corroded high strength rebars under dynamic loading.

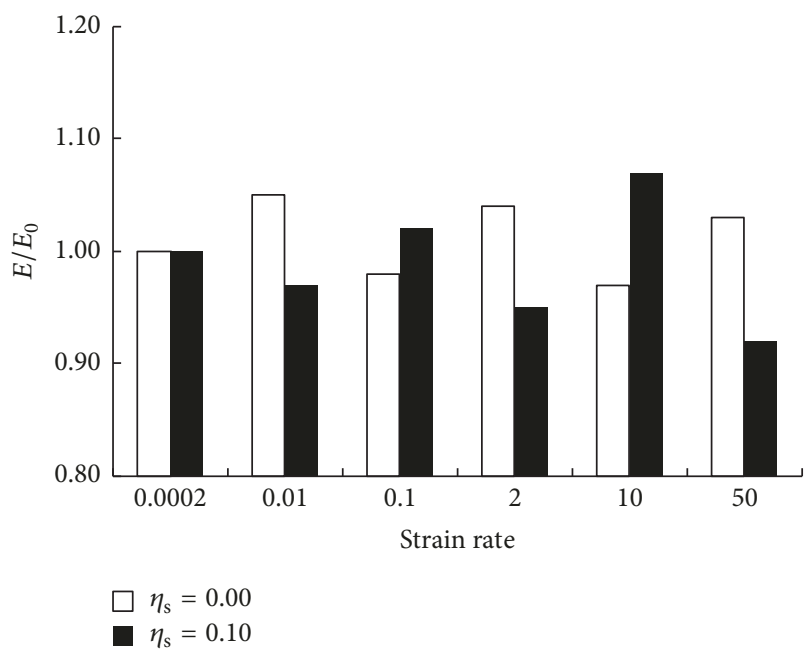

FIGURE 13: Influence of strain rate and corrosion degree on Young's modulus.

$f_{\mathrm{uc}, \mathrm{d}}$ are the yield and ultimate strengths of corroded rebars under dynamic loading $(\mathrm{MPa})$, respectively.

\subsection{Characteristic Parameters of Development of the Modified} $J$-C Model. The relationships of the characteristic parameters, such as Young's modulus, the yield strength $A, B, C, n$, and the ultimate strain, with the degree of corrosion and the strain rate, can be obtained through appropriate analysis of the test results, which is discussed in the following section.

4.3.1. Young's Modulus. Figure 13 shows the dependence of the relative Young's modulus for rebars on the strain rate and the average corrosion degree. The relative Young's modulus is the ratio of Young's modulus of a corroded rebar to that of a corresponding uncorroded rebar. It can be seen from Figure 13 that Young's modulus was not sensitive to the strain rate or the corrosion degree. For simplicity, it is assumed that Young's modulus keeps constant for corroded rebars under static and dynamic loading. Ignoring the influence 


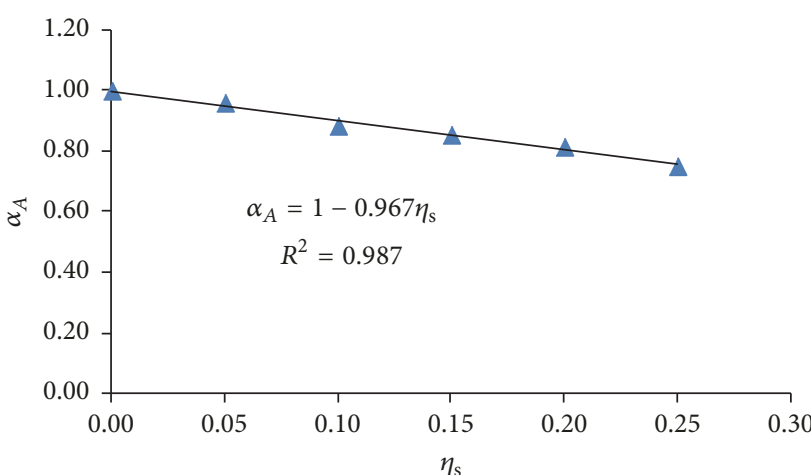

(a) Influence of corrosion degree on $A$ for corroded rebars

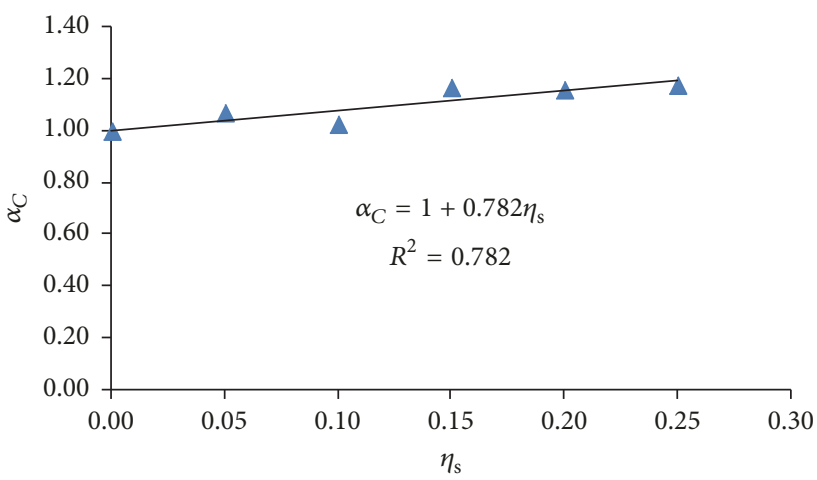

(c) Influence of corrosion degree on $C$ for corroded rebars

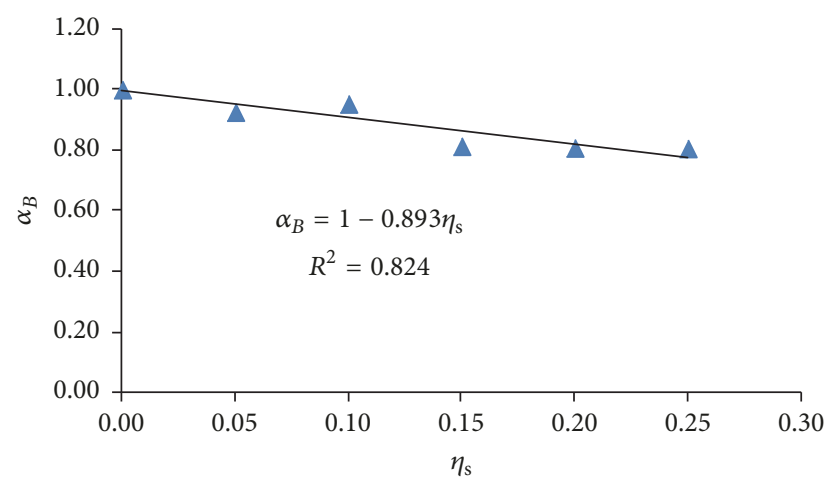

(b) Influence of corrosion degree on $B$ for corroded rebars

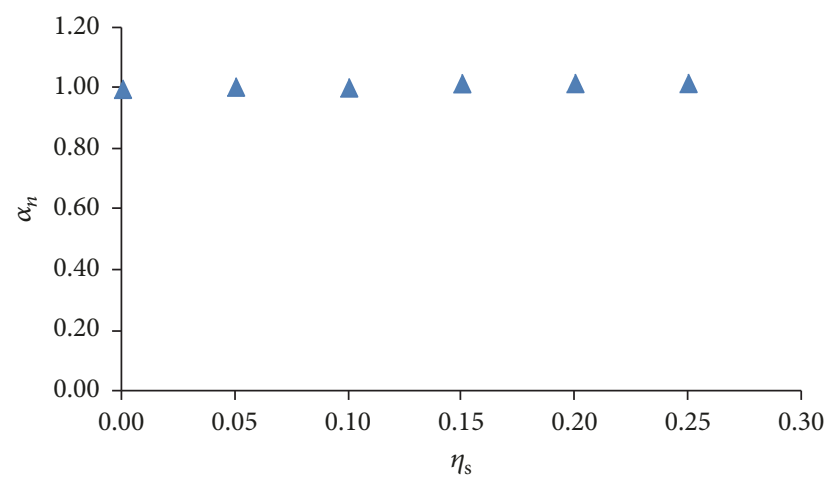

(d) Influence of corrosion degree on $n$ for corroded rebars

Figure 14: Influence of corrosion degree on $A, B, C$, and $n$ for corroded rebars.

TABle 4: Parameters for J-C model.

\begin{tabular}{lccccc}
\hline Steel & $\eta_{\mathrm{s}}$ & $A(\mathrm{MPa})$ & $B(\mathrm{MPa})$ & $C$ & $n$ \\
\hline \multirow{6}{*}{ HRB500 } & 0.00 & 558.49 & 6.788 & 0.0113 & 5.455 \\
& 0.05 & 536.58 & 6.287 & 0.0121 & 5.493 \\
& 0.10 & 494.63 & 6.469 & 0.0116 & 5.479 \\
& 0.15 & 478.34 & 5.527 & 0.0132 & 5.551 \\
& 0.20 & 456.46 & 5.489 & 0.0131 & 5.554 \\
& 0.25 & 421.11 & 5.477 & 0.0133 & 5.555 \\
\hline
\end{tabular}

of corrosion degree and strain rate on the elastic modulus, HRB500 steel bar takes $E=2.0 \times 10^{5} \mathrm{MPa}$.

4.3.2. Plastic Stage Model Parameters. According to the nominal yield strength, ultimate strength, the strain of the corroded steel measured under different strain rates, and the same corrosion degree from the strain rate of $0.0002 \mathrm{~s}^{-1}$, $0.1 \mathrm{~s}^{-1}$, and $10 \mathrm{~s}^{-1}$ the parameters of Johnson-Cook constitutive model of $A, B, C$, and $n$ were got by using multivariate nonlinear least squares regression analysis, as shown in Table 4.

The impacts of corrosion degree on the relative value of the parameters of $A, B, C$, and $n$ in the J-C model under dynamic loading are shown in Figure 14. It can be found that $A$ and $B$ decreased linearly with increases in the average corrosion degree as shown in (5a) and (5b); while the value of $B$ increased linearly with increases in the average corrosion degree and $n$ was not obvious. It can be expressed as (5a), (5b), and $(5 c)$. It is concluded that the strain rate effect of corroded steel bars decreases with the increase of corrosion degree

$$
\begin{aligned}
& \alpha_{A}=\frac{A}{A_{0}}=1-k_{A} \eta_{s}, \\
& \alpha_{B}=\frac{B}{B_{0}}=1-k_{B} \eta_{s} \\
& \alpha_{C}=\frac{C}{C_{0}}=1+k_{C} \eta_{s},
\end{aligned}
$$

where $A, B$, and $C$ are the basic parameters of corroded steel bars and $A_{0}, B_{0}$, and $C_{0}$ are parameters of the J-C model of the uncorroded steel bars; see Table 4 . And the relative values of the parameters $A, B$, and $C$, respectively, $k_{A}, k_{B}$, and $k_{C}$, are the relative coefficients of corrosion degree of each parameter.

Equations (4), (5a), (5b), and (5c) can be used to determine the parameters $A, B, C$, and $n$, and the corresponding yield strength and ultimate strength can be obtained according to (4) according to the strain and ultimate strain of the corroded steel bar under dynamic loading.

4.3.3. Hardening Strain. With corrosion degree increased, the yield plateaus of corroded high strength rebars shortened. When the corrosion degree reached a critical value, $\eta_{\mathrm{s}, \mathrm{cr}}$, the yield plateaus of corroded high strength rebars disappeared. If 
the influence of the strain rate on the deformability of rebars was ignored and the yield plateau shortens linearly in length with the development of corrosion degree, the hardening strain of corroded rebars can be calculated by using

$$
\varepsilon_{\mathrm{shc}, \mathrm{d}}= \begin{cases}\varepsilon_{\mathrm{syc}, \mathrm{d}}+\left(\varepsilon_{\mathrm{sh} 0, \mathrm{~d}}-\varepsilon_{\mathrm{sy} 0, \mathrm{~d}}\right) \cdot\left(1-\frac{\eta_{\mathrm{s}}}{\eta_{\mathrm{s}, \mathrm{cr}}}\right)=\frac{f_{\mathrm{yc}, \mathrm{d}}}{E_{\mathrm{sc}, \mathrm{d}}}+\left(\varepsilon_{\mathrm{sh} 0}-\frac{f_{\mathrm{y} 0, \mathrm{~d}}}{E_{\mathrm{s} 0, \mathrm{~d}}}\right) \cdot\left(1-\frac{\eta_{\mathrm{s}}}{\eta_{\mathrm{s}, \mathrm{cr}}}\right) & \left(\eta_{\mathrm{s}} \leq \eta_{\mathrm{s}, \mathrm{cr}}\right) \\ \varepsilon_{\mathrm{syc}, \mathrm{d}}=\frac{f_{\mathrm{yc}, \mathrm{d}}}{E_{\mathrm{sc}, \mathrm{d}}} & \left(\eta_{\mathrm{s}}>\eta_{\mathrm{s}, \mathrm{cr}}\right),\end{cases}
$$

where $\varepsilon_{\text {sy0,d }}$ and $\varepsilon_{\text {sh0,d }}$ are the yielding strain and hardening strain for uncorroded rebars, respectively; $f_{\mathrm{y} 0, \mathrm{~d}}$ and $f_{\mathrm{yc}, \mathrm{d}}$ are the yielding strengths of the uncorroded and corroded rebar specimens, respectively; and, $E_{\mathrm{s} 0, \mathrm{~d}}$ is Young's modulus for uncorroded rebars.

4.3.4. Ductility. The ultimate strains for specimens under dynamic loading are presented in Figure 15(a). As shown in the figure, no significant dependence of the ultimate strain was observed on the strain rate. Ignoring the effect of the strain rate, the ultimate strain of corroded rebars decreased significantly with the increasing corrosion degree, as shown in Figure 15(b). It can be expressed as

$$
\varepsilon_{\mathrm{suc}}=\alpha_{\delta \mathrm{c}} \cdot \varepsilon_{\mathrm{su} 0},
$$

where $\varepsilon_{\text {su0 }}$ is the ultimate strain of the uncorroded rebars, which can be chosen as 0.15 for HRB500 rebars based on the test results; $\varepsilon_{\text {suc }}$ is the ultimate strain of the corroded rebars; $\alpha_{\delta \mathrm{c}}$ is the ratio of the ultimate strain of corroded rebars to that of uncorroded rebars. Using regression analysis, it was determined that $\alpha_{\delta \mathrm{c}}=e^{-2.586 \eta_{\mathrm{s}}}$ for corroded HRB500 rebars.

\section{Comparison of J-C Model Results and Experimental Results}

5.1. Comparison with Test Results. Table 5 shows the comparisons between the predicted values of the nominal yield strength $f_{\text {syc }}$ and ultimate strength $f_{\text {suc }}$ for the corroded high strength rebars of the modified J-C model with experiments. It can be seen that the predicted value and experimental value were in good agreement, which showed that the modified J$\mathrm{C}$ model was effective. As can be seen from Table 5, most of the errors of high strength rebars under strain rates 2 to $50 \mathrm{~s}^{-1}$ were no more than $5 \%$.

5.2. Comparison with the Existing Models. The predicted values of DIF (dynamic increase factor) based on the above modified J-C model were compared with the dynamic constitutive model of the yield strength and ultimate strength for uncorroded rebars with existing model in literature [23] and CEB model [24]. As shown in Figure 16, the DIF of yield strength and ultimate strength were slightly larger than the literature value. This may be caused by the difference of steel chemical composition and manufacturing process. The plastic strain rate is $0.0002 \mathrm{~s}^{-1}$ in the modified $\mathrm{J}-\mathrm{C}$ model; the DIF of the static loading converges to 1 ; the J-C model can be used for description of the mechanical behavior of HRB500 rebars with strain rates $0.0002-50 \mathrm{~s}^{-1}$.

\section{Conclusions}

Corrosion has been found to be the most predominant cause for failures of RC structure. The tensile behaviors of corroded steel bars are important in the capacity evaluation of corroded reinforced concrete structures. High strength corroded steel bars were tested in this study to investigate their tensile behaviors under dynamic loading. The dynamic tensile testing system was used to study the mechanical behavior of the corroded high strength steel bars under dynamic loading, and the modified J-C Model was established based on JohnsonCook equation. The following conclusions can be drawn.

(1) From the nominal stress-strain curves of corroded high strength steel bars, it was observed that both strength and deformation capacities decreased with increasing corrosion. However, this trend was less clear for the deformation capacity than for the strength capacity. As supported by $3 \mathrm{D}$ scan results, this is due to the fact that the strength capacity was affected mainly by the minimum cross-sectional area, while the deformation capacity was affected by more factors, including the minimum cross-sectional area and the distribution of cross-sectional areas along the bar.

(2) With increasing strain rates, the nominal yield and ultimate strengths increase, while its effects on the yield plateau and the ultimate deformation are not obvious. Based on the analysis of Johnson-Cook model parameters $A, B, C$, and $n$ under different corrosion degrees, it is found that the strain rate effect of the yield strength and ultimate strength decreases with the increase of corrosion rate.

(3) The modified J-C model was used to describe the corroded high strength rebars under dynamic loading. The modified model fits well with experiments, and the max average relative error is $5 \%$. Therefore, this modified J$\mathrm{C}$ model provides a new modeling idea and approach for the corroded high steel under dynamic loading involving corrosion degree and strain rate.

\section{Abbreviations}

$A_{\mathrm{Fe}}$ : The atomic mass of iron $(A=56 \mathrm{~g})$

$t_{\mathrm{c}}$ : The corrosion duration (days)

$Z$ : The valence of iron, which is 2 in this case (iron)

F: $\quad$ Faraday's constant (96500 A·s) 


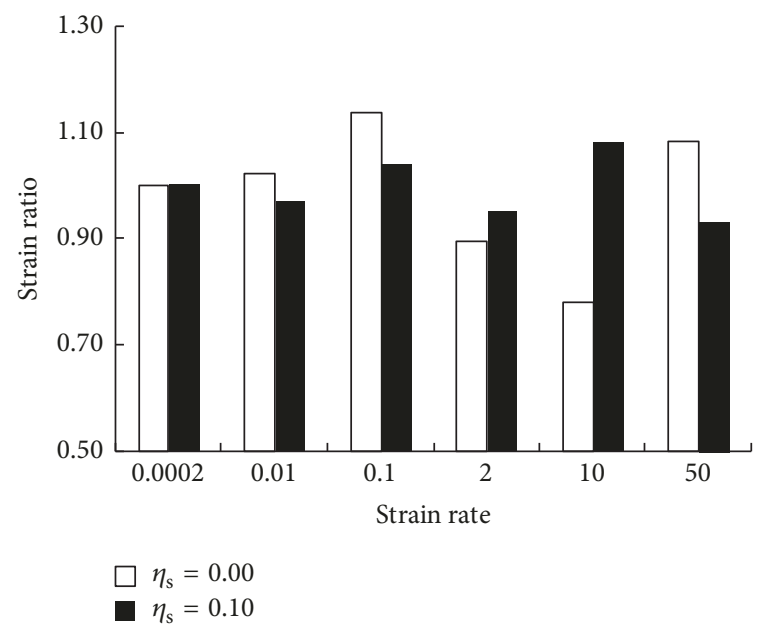

(a) Relative ultimate strain under different strain rates

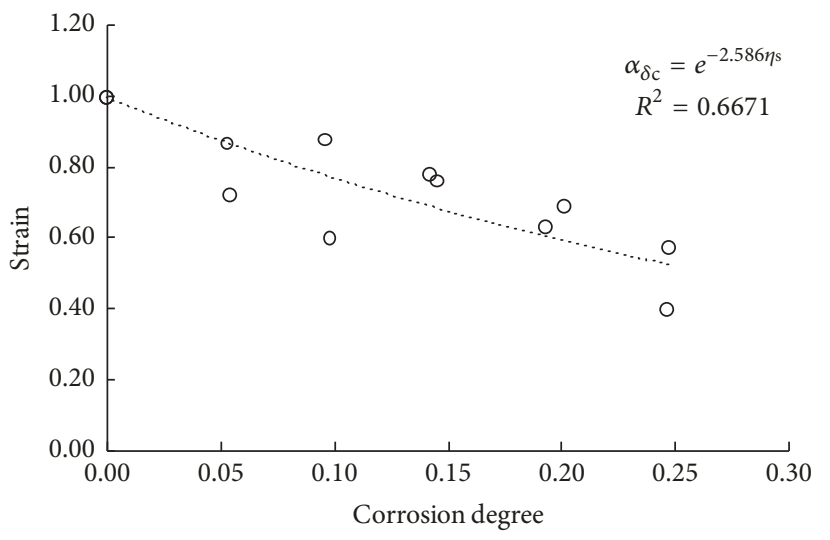

(b) Relative ultimate strain for corroded steel bars

FIGURE 15: Relative ultimate strain.

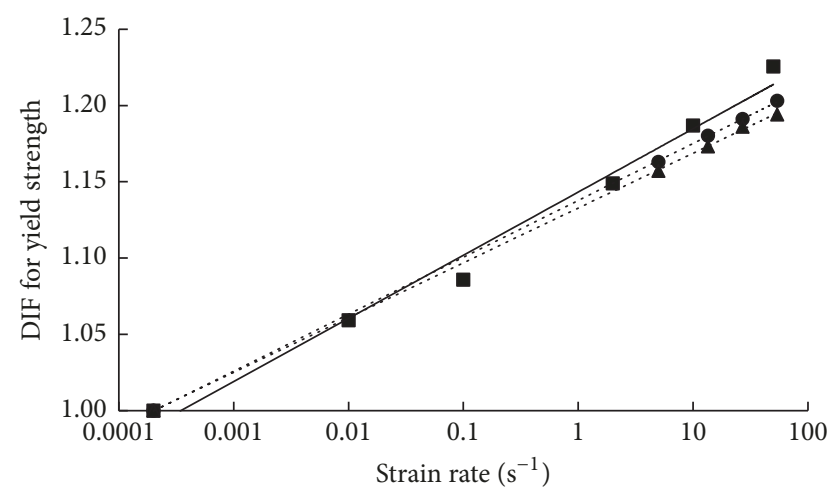

- J-C model

- Lin model

$\triangle \mathrm{CBE}$

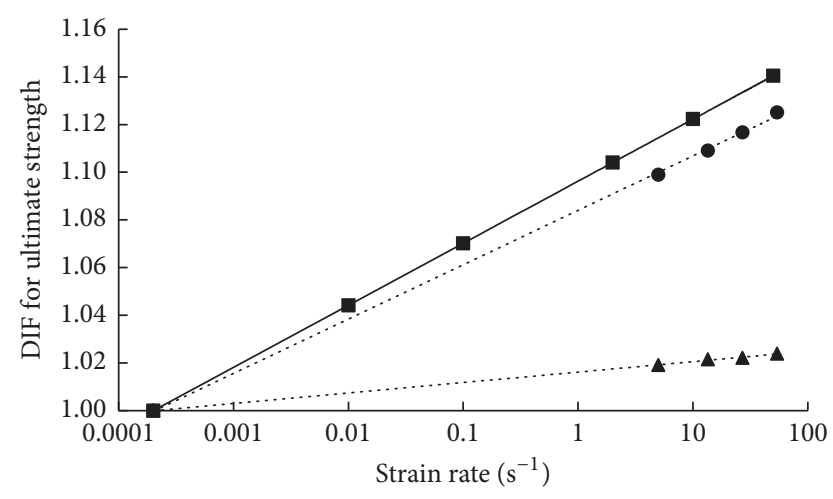

- J-C model

- Lin model

$\triangle \mathrm{CBE}$

(a) DIF for yield strength

(b) DIF for ultimate strength

FIGURE 16: Comparison of yield strength and ultimate strength between modified and existing models.

TABLE 5: Comparison of the results from J-C model and values from test.

\begin{tabular}{|c|c|c|c|c|c|c|}
\hline Specimen & $\begin{array}{c}\text { Test } \\
(\mathrm{MPa})\end{array}$ & $\begin{array}{c}\mathrm{J}-\mathrm{C} \\
(\mathrm{MPa})\end{array}$ & $\begin{array}{c}\text { Error } \\
(\%)\end{array}$ & $\begin{array}{c}\text { Test } \\
(\mathrm{Mpa})\end{array}$ & $\begin{array}{c}\mathrm{J}-\mathrm{C} \\
(\mathrm{MPa})\end{array}$ & $\begin{array}{c}\text { Error } \\
\% \\
\end{array}$ \\
\hline HSO0-2 & 573.47 & 599.62 & 4.6 & 696.21 & 687.68 & -1.2 \\
\hline HS00-10 & 592.31 & 620.77 & 4.8 & 706.9 & 699.01 & -1.1 \\
\hline HSO0-50 & 611.66 & 636.93 & 4.1 & 727.78 & 710.34 & -2.4 \\
\hline HS05-10 & 562.26 & 558.49 & -0.7 & 664.63 & 622.86 & -6.3 \\
\hline HS15-10 & 503.18 & 478.34 & -4.9 & 580.09 & 591.58 & 2.0 \\
\hline HS20-10 & 479.25 & 456.46 & -4.8 & 557.17 & 552.93 & -0.8 \\
\hline HS25-10 & 444.1 & 456.46 & 2.8 & 519.99 & 521.10 & 0.2 \\
\hline HS10-2 & 496.56 & 517.48 & 4.3 & 611.66 & 612.01 & 0.1 \\
\hline HS10-10 & 522.54 & 546.05 & 4.5 & 625.92 & 622.33 & -0.6 \\
\hline HS10-50 & 528.14 & 565.95 & 7.2 & 644.77 & 632.65 & -1.9 \\
\hline
\end{tabular}

Note. $(1)$ Error $=($ Value from the model - value from tests $) /$ value from tests. 
$i$ : The density of impressed current $\left(\mathrm{A} / \mathrm{cm}^{2}\right)$

$\rho: \quad$ The mass density of iron $\left(\mathrm{g} / \mathrm{cm}^{3}\right)$

$r: \quad$ The radius of to-be-corroded rebars $(\mathrm{mm})$

$\eta_{\mathrm{sp}}: \quad$ The targeted average corrosion degree

$\eta_{s}: \quad$ The average corrosion degree

$\eta_{s, \max }:$ The maximum corrosion degree

$\eta_{s, \mathrm{cr}}:$ The critical average degree of corrosion

$E_{\mathrm{s} 0}$ : Young's modulus for an uncorroded rebar under static loading (MPa)

$E_{\mathrm{s} 0, \mathrm{~d}}$ : Young's modulus for an uncorroded rebar under dynamic loading (MPa)

$F_{\mathrm{y} 0}$ : The yielding load of an uncorroded rebar or a corroded rebar $(\mathrm{kN})$

$F_{\mathrm{u} 0}$ : The ultimate load of an uncorroded rebar or a corroded rebar $(\mathrm{kN})$

$f_{\mathrm{yc}}$ : The nominal yield strength of a corroded rebar $(\mathrm{MPa})$

$f_{\mathrm{uc}}$ : The nominal ultimate strength of a corroded rebar $(\mathrm{MPa})$

$f_{\mathrm{yc}, \mathrm{st}}$ : The yielding strength of a corroded rebar under static load (MPa)

$f_{\mathrm{uc}, \mathrm{st}}$ : The ultimate strength of a corroded rebar under static load $(\mathrm{MPa})$

$f_{\mathrm{y} 0, \mathrm{st}}:$ The yield strength of uncorroded rebar under static load (MPa)

$\sigma: \quad$ The corresponding average engineering stress (MPa)

$\widetilde{\sigma}: \quad$ The true stress (MPa)

$\sigma_{s}: \quad$ The Von Mises equivalent flow stress (MPa)

$\sigma_{\text {sc,d }}:$ The Von Mises equivalent flow stress of the corroded rebars (MPa)

A: $\quad$ The yield stress at a given reference temperature and a given reference strain rate $(\mathrm{MPa})$

B: $\quad$ The coefficient of strain hardening

$C$ : The coefficient of strain rate hardening

$n: \quad$ The strain hardening exponent

$A_{0}$ : The parameter of the J-C model of the uncorroded steel bars (MPa)

$B_{0}$ : The parameter of the J-C model of the uncorroded steel bars

$C_{0}$ : The parameter of the J-C model of the uncorroded steel bars

$k_{A}$ : The relative coefficient of corrosion degree of $A$

$k_{B}$ : The relative coefficient of corrosion degree of $B$

$k_{C}$ : The relative coefficient of corrosion degree of $C$

$\dot{\varepsilon}_{\mathrm{sc}, \mathrm{st}}:$ The strain rate of a rebar under static load

$\varepsilon^{p}: \quad$ The equivalent plastic strain

$\dot{\varepsilon}_{0}^{*}$ : The dimensionless strain rate with $\dot{\varepsilon}$ being the strain rate and $\dot{\varepsilon}_{0}$ the reference strain rate

$\varepsilon: \quad$ The corresponding average engineering strain

$\widetilde{\varepsilon}: \quad$ The true strain $\varepsilon_{\text {su0 }}$ : The ultimate strain of the uncorroded rebar

$\varepsilon_{\text {suc }}:$ The ultimate strain of the corroded rebar

$\alpha_{\delta c}$ : The ratio of the ultimate strain of corroded rebars to that of uncorroded rebars

$T: \quad$ The experimental temperature $\left({ }^{\circ} \mathrm{C}\right)$

$T_{\mathrm{r}}$ : The room temperature $\left({ }^{\circ} \mathrm{C}\right)$

$T_{\mathrm{m}}$ : The melting temperature of the materials $\left({ }^{\circ} \mathrm{C}\right)$.

\section{Conflicts of Interest}

The authors declare that there are no conflicts of interest regarding the publication of this paper.

\section{Acknowledgments}

This study was financially supported by the National Natural Science Foundation of China (51608393).

\section{References}

[1] A. K. Azad, S. Ahmad, and B. H. A. Al-Gohi, "Flexural strength of corroded reinforced concrete beams," Magazine of Concrete Research, vol. 62, no. 6, pp. 405-414, 2010.

[2] C. A. Apostolopoulos, "The effect of ribs on the mechanical behavior of corroded reinforcing steel bars S500s under lowcycle fatigue," Materials and Structures/Materiaux et Constructions, vol. 41, no. 5, pp. 991-999, 2008.

[3] W. Zhang, X. Song, X. Gu, and S. Li, "Tensile and fatigue behavior of corroded rebars," Construction and Building Materials, vol. 34, pp. 409-417, 2012.

[4] J. A. González, C. Andrade, C. Alonso, and S. Feliu, "Comparison of rates of general corrosion and maximum pitting penetration on concrete embedded steel reinforcement," Cement and Concrete Research, vol. 25, no. 2, pp. 257-264, 1995.

[5] Y. G. Du, L. A. Clark, and A. H. C. Chan, "Residual capacity of corroded reinforcing bars," Magazine of Concrete Research, vol. 57, no. 3, pp. 135-147, 2005.

[6] J. Cairns, G. A. Plizzari, Y. Du, D. W. Law, and C. Franzoni, "Mechanical properties of corrosion-damaged reinforcement," ACI Materials Journal, vol. 102, no. 4, pp. 256-264, 2005.

[7] R. Palsson and M. S. Mirza, "Mechanical response of corroded steel reinforcement of abandoned concrete bridge," ACI Structural Journal, vol. 99, no. 2, pp. 157-162, 2002.

[8] Y.-C. Ou, H.-D. Fan, and N. D. Nguyen, "Long-term seismic performance of reinforced concrete bridges under steel reinforcement corrosion due to chloride attack," Earthquake Engineering \& Structural Dynamics, vol. 42, no. 14, pp. 2113-2127, 2013.

[9] M. G. Stewart, "Mechanical behaviour of pitting corrosion of flexural and shear reinforcement and its effect on structural reliability of corroding RC beams," Structural Safety, vol. 31, no. 1, pp. 19-30, 2009.

[10] M. Beck, A. Burkert, J. Harnisch et al., "Deterioration model and input parameters for reinforcement corrosion," Structural Concrete, vol. 13, no. 3, pp. 145-155, 2012.

[11] I. Rohr, H. Nahme, and K. Thoma, "Material characterization and constitutive modelling of ductile high strength steel for a wide range of strain rates," International Journal of Impact Engineering, vol. 31, no. 4, pp. 401-433, 2005. 
[12] A. Filiatrault and M. Holleran, "Stress-strain behavior of reinforcing steel and concrete under seismic strain rates and low temperatures," Materials and Structures, vol. 34, no. 238, pp. 235-239, 2001.

[13] P. Soroushian and K. B. Choi, "Steel mechanical properties at different strain rates," Journal of Structural Engineering, vol. 113, no. 4, pp. 663-672, 1987.

[14] F. Lin, X. L. Gu, X. X. Kuang, and X. J. Yin, "Constitutive models for reinforcing steel bars under high strain rates," Journal of Building Materials, vol. 11, no. 1, pp. 14-20, 2008.

[15] W.-P. Zhang, H. Chen, and X.-L. Gu, "Tensile behaviour of corroded steel bars under different strain rates," Magazine of Concrete Research, vol. 68, no. 3, pp. 127-140, 2016.

[16] G. R. Johnson and W. H. Cool, "A constitutive model and data for metals subjected to large strain, high strain rates and high temperatures," in Proceedings of the 7th International Symposium on Ballistics, The Hague, Netherlands, April 1983.

[17] ASTM, in ASTM E8/E8M-09 Standard Test Methods for Tension Testing of Metallic Materials, pp. 1-25, ASTM International, West Conshohocken, Pa, USA, 2009.

[18] A. A. Almusallam, "Effect of degree of corrosion on the properties of reinforcing steel bars," Construction and Building Materials, vol. 15, no. 8, pp. 361-368, 2001.

[19] Y.-C. Ou, Y. T. T. Susanto, and H. Roh, "Tensile behavior of naturally and artificially corroded steel bars," Construction and Building Materials, vol. 103, pp. 93-104, 2016.

[20] Y. S. Yuan, Y. S. Ji, and S. P. Shah, "Comparison of two accelerated corrosion techniques for concrete structures," ACI Structural Journal, vol. 104, no. 3, pp. 344-347, 2007.

[21] T. A. El Maaddawy and K. A. Soudki, "Effectiveness of impressed current technique to simulate corrosion of steel reinforcement in concrete," Journal of Materials in Civil Engineering, vol. 15, no. 1, pp. 41-47, 2003.

[22] ASTM, in ASTM G1-03 Standard Practice for Preparing, Cleaning, and Evaluating Corrosion Test Specimens, pp. 1-9, ASTM International, West Conshohocken, Pa, USA, 2003.

[23] F. Lin, Y. Dong, and X. Gu, "Dynamic constitutive models for high strength reinforcing steel bar HRB500," Journal of Building Materials, vol. 17, no. 4, pp. 592-597, 2014.

[24] J. Eibl, "Concrete structures under impact and impulsive loading: synthesis report," Tech. Rep., Comité Euro-International du Béton, Lausanne, Switzerland, 1988. 


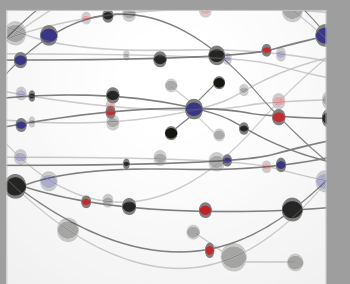

The Scientific World Journal
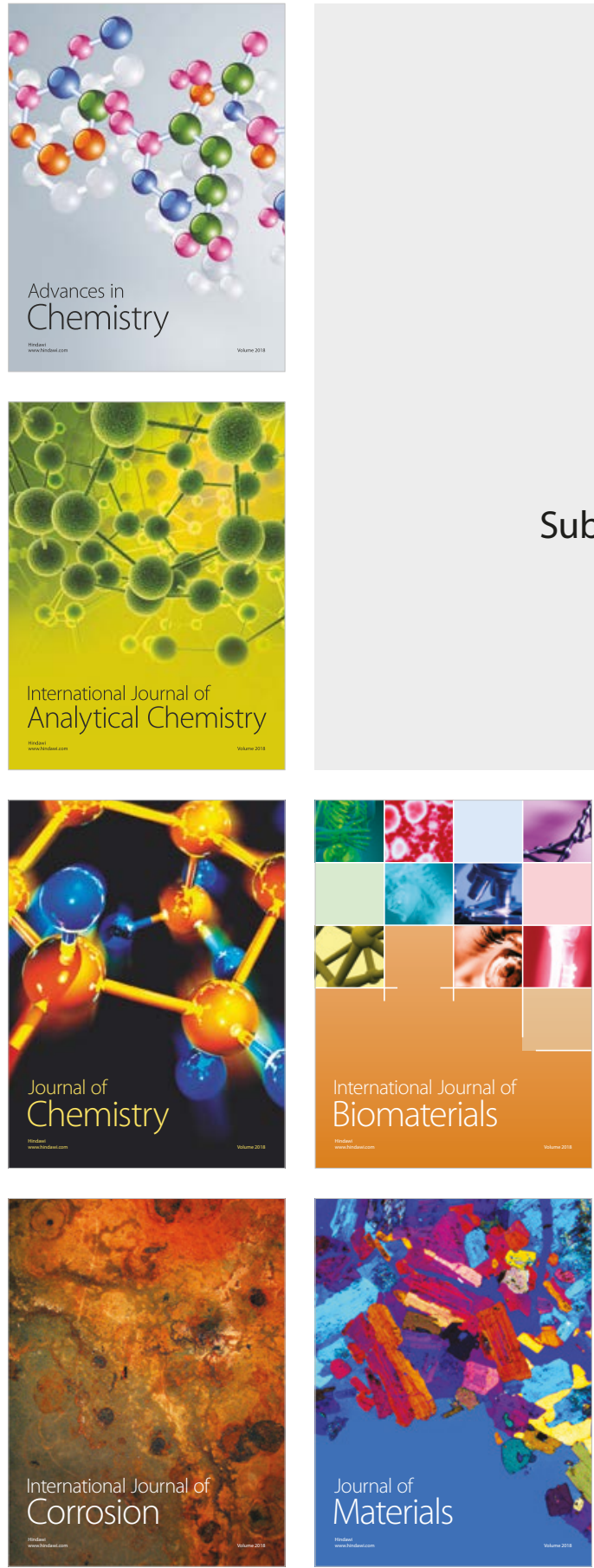

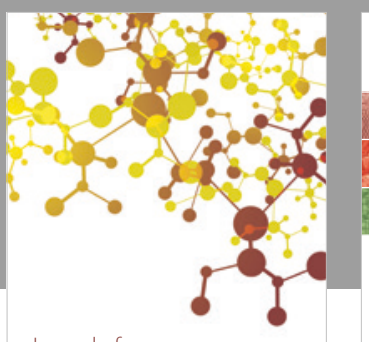

Journal of

Applied Chemistry
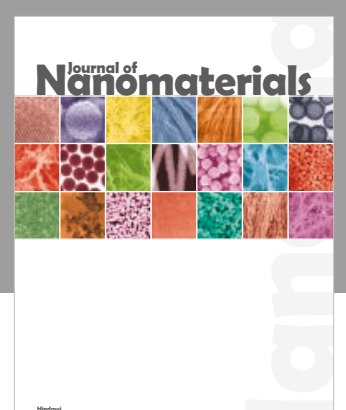

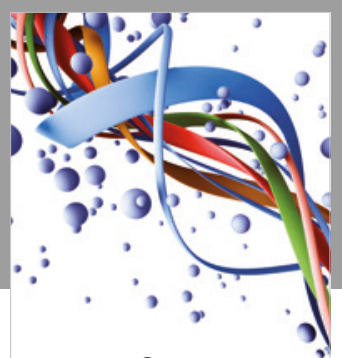

Scientifica

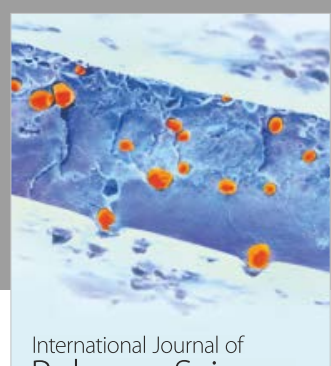

Polymer Science

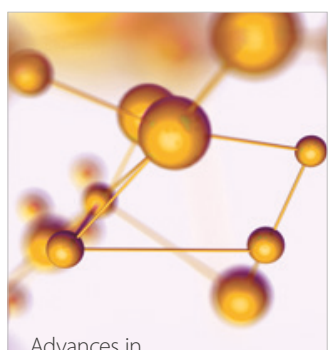

Physical Chemistry
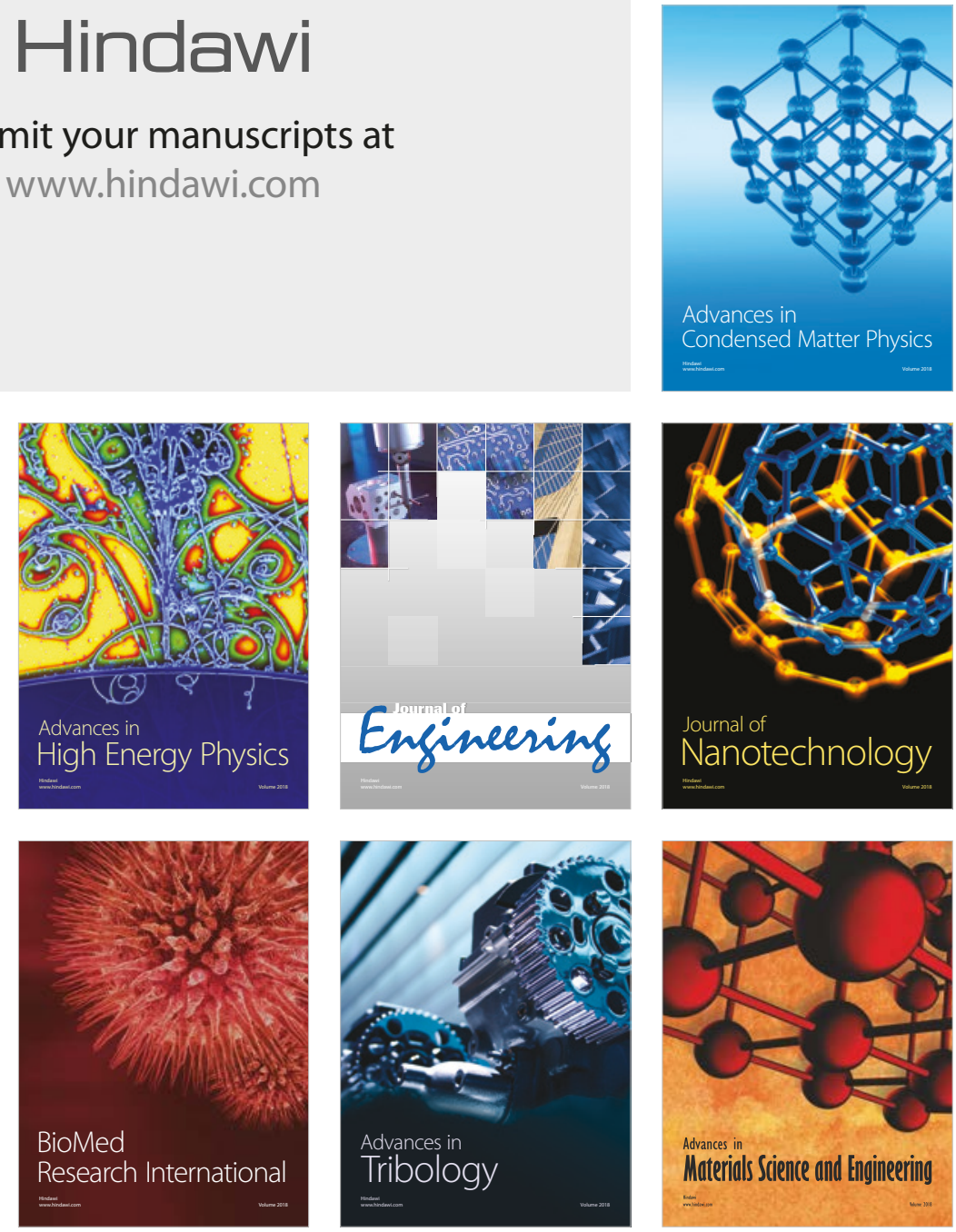